International Journal of Cancer Studies \& Research (IJCR) ISSN: 2167-9118

\title{
Endoscopic Mucosal Resection after Circumferential Mucosal Incision of Large Colorectal Tumors: Comparison With Endoscopic Submucosal Dissection
}

\section{Research Article}

Mochizuki $\mathrm{Y}^{1 *}$, Saito $\mathrm{Y}^{1}$, Inatomi $\mathrm{O}^{2}$, Fujiyama $\mathrm{Y}^{2}$, Bamba S², Ishida $\mathrm{M}^{3}$, Tsujikawa $\mathrm{T}^{4}$, Andoh $\mathrm{A}^{5}$

${ }^{1}$ Division of Digestive Endoscopy, Shiga University of Medical Science, Seta-Tukinowa, Otsu 520-2192, Japan.

${ }^{2}$ Department of Internal Medicine, Shiga University of Medical Science, Seta-Tukinowa, Otsu 520-2192, Japan.

${ }^{3}$ Department of Clinical Laboratory Medicine, Shiga University of Medical Science, Seta-Tukinowa, Otsu 520-2192, Japan.

${ }^{4}$ Division of Comprehensive Internal Medicine, Shiga University of Medical Science, Shiga University of Medical Science, Seta-Tukinowa, Otsu 520-2192, Japan.

${ }^{5}$ Division of Mucosal Immunology, Graduate School of Medicine, Shiga University of Medical Science, Seta-Tukinowa, Otsu 520-2192, Japan.

\section{Abstract}

Background: Endoscopic mucosal resection is widely used for treating superficial colorectal carcinomas or premalignant colorectal tumors. Piecemeal resection and local recurrence are frequent with endoscopic mucosal resection for $>20$-mm-diameter tumors. Endoscopic submucosal dissection, which facilitates en bloc resection of large colorectal tumors, is useful for superficial colorectal tumors. In our hospital, endoscopic mucosal resection after circumferential mucosal incision was used for colorectal tumorswith a diameter of $20-30 \mathrm{~mm}$.

Objective: To determine the efficacy and safety of endoscopic mucosal resection after circumferential mucosal incision.

Design: Retrospective clinical trial at a single center

Settings: ShigaUniversity of Medical Science

Patients: 77 colorectal tumors (69 patients) with a diameter of 20-30 mmendoscopically treated between January 2010 and May2012 at Shiga University of Medical Science.

Interventions: Endoscopic submucosal dissection and endoscopic mucosal resection after circumferential mucosal incision.

Main Outcome Measures: En bloc resection rate, procedure time, complications

Results: ESD was associated with longer procedure times compared with C-EMR $(\mathrm{p}<0.005)$. En bloc resection, complete curative resection, and perforation rates were similar in both groups Delayed bleeding was limited to the ESD group (2.1\%).Histopathological analysis revealed that the incidence of adenoma was lower in the ESD group than in the C-EMR group $(\mathrm{p}=0)$. Mucosal cancer was more frequent in the ESD group $(\mathrm{p}=0)$. The nonlifting sign was seen in $16.7 \%$ patients with laterally spreading tumors of nongranular type in the en blocCEMR group and 100\% patients with laterally spreading tumors of nongranular type in the piecemeal C-EMR group $(p=0.035)$.

Limitations: A single-centerretrospective study

Conclusions: C-EMRand ESD were equally effective for treating colorectal tumors with a diameter of $20-30 \mathrm{~mm}$.

Key Words: Endoscopic Submucosal Dissection; Endoscopic Mucosal Resection; Cutting Endoscopic Mucosal Resection; Local Recurrence; Piecemeal Resection;Large Colorectal Tumors; Colorectal Neoplasia.

\section{*Corresponding Author:}

Yosuke Mochizuki

Division of Digestive Endoscopy, Shiga University of Medical Science, Seta-Tukinowa, Otsu 520-2192, Japan.

E-mail:yousuke@belle.shiga-med.ac.jp

Received: April 16, 2013

Accepted: April 29, 2013

Published: April 30, 2013

Citation: Mochizuki Y et al (2013) Endoscopic mucosal resection after circumferential mucosal incision of large colorectal tumors: comparison with endoscopic submucosal dissection. Int J Cancer Stud Res. 2(2), 17 25. doi: http://dx.doi.org/10.19070/2167-9118-130003

Copyright: Yosuke Mochizuki (C 2013. This is an open-access article distributed under the terms of the Creative Commons Attribution License, which permits unrestricted use, distribution and reproduction in any medium, provided the original author and source are credited.

\section{Introduction}

Endoscopic mucosal resection (EMR) is indicated for treating superficial colorectal tumors because of its minimal invasiveness [1-5]. Conventional EMR techniques are currently used for resecting laterally spreading tumors (LSTs) [6-9]. However, incomplete EMR causes local recurrence [10-12]. Endoscopic submucosal dissection (ESD), which enables en bloc resection regardless of tumor size, has recently been reported to be useful for treating superficial colorectal tumors [9, 13-19],butis not widely used as 
standard therapy because it is technically demanding.

In our hospital, EMR after circumferential mucosal incision (CEMR), which is performed after mucosal resection around the tumor, was used for treating large colorectal tumors before ESD was introduced. Causes of local recurrence in EMR may include lateral slip of the snare in the tumor margin. Compared with conventional EMR, C-EMR allows en bloc resection of larger tumors because it facilitates grasping of the tumor by decreasing the area to be resected and ensures clear lateral margins by incorporating a circumferential mucosal incision as a first step.These procedures may reduce the local recurrence rate. Few studies have compared C-EMR and ESD for $\geq 20$-mm-diameter colorectal tumors.This retrospective study evaluated the usefulness and outcomes of both techniques.

\section{Materials and Methods}

\section{Patient selection}

In total, 653 colorectal tumors were resected using conventional endoscopy (EMR, C-EMR, or ESD) between January and May 2012 at Shiga University of Medical Science. Of these, 97 tumorshad a diameter of $20-30 \mathrm{~mm}$. Four of 97 tumors in which conventional EMR was performed and 16tumors in whichfollow-up colonoscopy was not possible were excluded. Thus, 77 colorectal tumorswith a diameter of $20-30 \mathrm{~mm}$ for whichfollow-up colonoscopy was performed at least once were included in this retrospective study (Fig. 1).

The tumors were divided into two groups according to the treatmenttype: ESD (47tumors in 39 patients) and C-EMR groups (30 tumors in 30 patients). Tumor morphology, size, and location, procedure times, en bloc resection rate, complete resection rate, perforation rate, incidence of delayed bleeding, local recurrence rate, and histopathological findings were evaluated for both groups.

\section{Definitions}

En bloc resection was defined as one-piece endoscopic resection of the entire tumor with free lateral and vertical margins onhistopathological examination. Complete resection was achieved in the following cases: adenoma- or carcinoma-free lateral and vertical margins on histopathological examination, intramucosal or submucosal carcinoma invasion $<1000 \mu \mathrm{m}$ from the muscularis mucosa, no evidence of lymphatic or vascular invasion, no evidence of tumor budding, and moderately to well-differentiated histological type.

Procedure times were measured from thesubmucosal injection of solution tocompletion of prophylactic hemostasis aftertumor resection. Delayed bleeding was defined as hematochezia $\geq 24 \mathrm{~h}$ after resection,requiring endoscopic hemostasis. Perforation was defined as a defect in the muscle layer detected during treatment or abdominal pain and fever with free air visible on computed tomography (CT).

\section{Endoscopic treatment}

The following endoscopes were used for diagnosis: CF-Q260AI, CF-Q240AI, CF-H260AZI, PCF-Q260AI, PCF-Q260JI, and PCF-Q260AZI (Olympus Optical Co., Ltd., Tokyo, Japan). Threeendoscopistshighly experienced in diagnostic and therapeutic colonoscopy diagnosed and treated all cases. The tumors were morphologically divided according to the Paris classification into LSTs and superficial and protruding tumors [20].LSTs were defined as $>10$-mm-diameter tumors with a granular (sometimes nodular) or nongranular surface pattern. They were characterized by lateral, circumferential, and less vertical growth through the colonic wall.

After tumor identification using white-light imaging, massive submucosal invasion were evaluated on the basis of obvious deep depression, hardened wall, fold convergence, two-step protrusion, expansive appearance, and non-neoplastic mucosa at the rising edge of the tumor with wall thickening. Surgical resection was selected for tumors with massive submucosal invasion. Tumors with invasive patterns observed using high-magnification chromoendoscopy or those with disruptions or thinning of the third layer corresponding to the submucosal layer on endoscopic ultrasound were not eligible for endoscopic curative resection and were surgically treated.

Endoscopes used for ESD and C-EMR included PCF-Q260JI and PCF-Q260AZI with the transparent disposable attachment

Figure 1: Flow chart showing the treatment paths for patients in this study

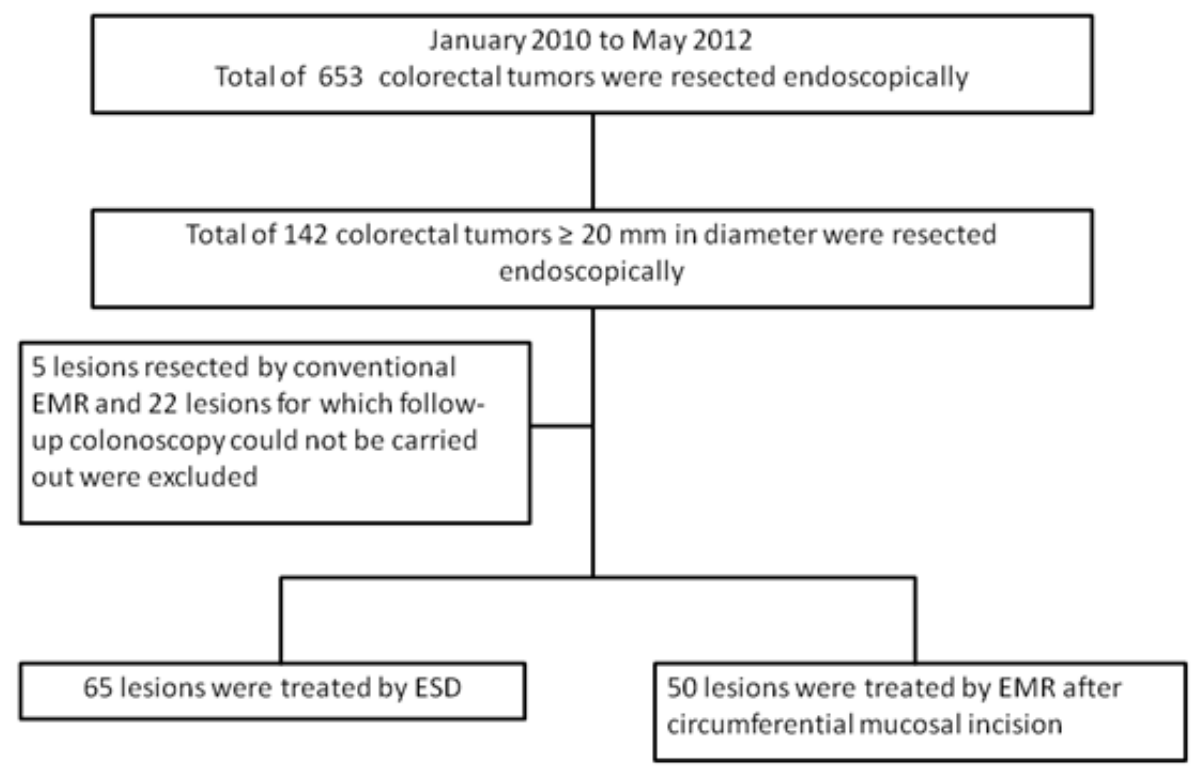


(Olympus Optical Co., Ltd., Tokyo, Japan) fitted on the endoscope tip to obtain a constant view and maintain tension on the connective tissue.

All endoscopic treatmentswereadministered by three experienced endoscopistsat our hospital. ESD and C-EMR were performed under sedation with periodic intravenous midazolam (0.05-0.1 $\mathrm{mg} / \mathrm{kg} / \mathrm{h}$ ) and propofol ( $2 \mathrm{mg} / \mathrm{kg} / \mathrm{h}$ )administration, while monitoring blood pressure, heart rate, and blood oxygen saturation levels. To avoid postoperative complications, the patients were hospitalized for 3-5 days after surgery.

\section{ESD procedure}

After tumor detection and washing away of surface mucus, $0.4 \%$ indigo carmine dye was sprayed over the tumor to delineate its margins before ESD. For submucosal injection, hyaluronic acid or a mixed glycerinsolution, epinephrine, and indigo carmine dye were used. After submucosal injection, mucosal incisions measuringhalf the tumor circumference were made approximately 5 $\mathrm{mm}$ from the tumor using a needle knife (KD-10Q-1; Olympus Optical Co., Ltd., Tokyo, Japan) with an electrosurgical generator (VIO300D; ERBE Elektromedizin GmbH,Tübingen, Germany) in dry cut mode. Subsequently,a hook knife (KD-620QR; Olympus Optical Co., Ltd., Tokyo, Japan) or dual knife (KD-650L/Q; Olympus Optical Co., Ltd., Tokyo, Japan) was used to dissect the thickened submucosal layer from the muscle layer. After some dissection of the submucosal layer, additional mucosal incisions were made around the entire tumor circumference.Submucosalinjections were repeated as required, and the submucosallayer was continuously dissected until the entire tumor was removed. For bleeding control or prophylaxis against bleeding, hemostatic forceps (FD-411QR; Olympus Optical Co., Ltd., Tokyo, Japan) were used to coagulate visible vessels on the tumor bed after resection in softcoagulation mode.

\section{C-EMR procedure}

C-EMR was performed according to the same protocol that was used for ESDuntil the step involving submucosal injection. After the tumor was lifted, a needle knife with the electrosurgical generator in drycut modewas used to make an incision around the entire tumor circumference approximately $5 \mathrm{~mm}$ outside the tumor boundary and dissect the submucosal layer to some extent. Subsequently, a submucosal injection was administered to elevate the tumor. A $27-\mathrm{mm}$ or 33-mm snare wire (Captivator ${ }^{\circledR}$ I or II; Boston Scientific Japan, Tokyo, Japan) with the electrosurgical generator in Endocut Q mode was used to resectthe tumor.The site was examined for residual tumor tissue after snare resection, and additional resection was performed as required. Hemostatic forceps or argon plasma coagulation was used to ablate residual tumors that were difficult to remove with additional snaring. Finally, a hemostatic forceps was used in the softcoagulation mode to control hemorrhage or prophylactically ablate the exposed vessels.

\section{Pathological assessments}

Theresectedsampleswerediagnosedbyhematoxylin-eosinstaining. Electron microscopywas used by one pathologistat our hospital toevaluatealltumors. Tumors were classified according to the Vienna classification system[21]. Histological type, depth of invasion, lateral and vertical resection margins, and level of lymphovascular involvement were evaluated microscopically. Shallow submucosal invasionwas defined as tumor depth $<1000 \mu \mathrm{m}$ from the muscularis mucosae. Massive submucosal invasion was defined as tumor depth $\geq 1000 \mu \mathrm{m}$.

\section{Follow-up colonoscopy}

After resection, follow-up colonoscopy was performed at 6 months in cases of completely resected adenomas and at 3 months in cases of ESD, cancer, and piecemeal resection. Cases without local recurrence on initial follow-up endoscopy were followed up once every year. Local recurrence was defined as cancer or adenoma tissue detection on pathological examination of the biopsied samples.

\section{Statistical analysis}

Data are presented as means and standard deviations (SD). The SAS Statistical package (SAS Institute, Tokyo, Japan) was used for comparing baseline characteristics between both groups. The ttest and chi-square test were used for continuous and dichotomous variables, respectively. Significance level was set at $5 \%$ for all analyses; $p$ values were two-sided.

\section{Ethics}

Because EMR for colorectal tumorsis used worldwide as a standard therapy, C-EMR, which has same procedural steps such as mucosal incision in ESD and snaring in EMR, was not a special procedure; therefore, the data were prospectively evaluated, and all endoscopic procedures were performed without the approval of our hospital's ethics committee. However, written informed consent was obtained from all patients for colonoscopic treatment as well as all the scheduled follow-up examinations.

\section{Results And Discissions}

The patients' clinical characteristics are presented in Table 1.

\section{Their clinical outcomes are described in Table 2.}

No differences were observed between both groups in terms of gender, age, macroscopic type, or tumor location. LST of granular type (LST-G) was more frequent in the C-EMR group than in the ESD group $(p=0.0068)$. LST of nongranular type (LST-NG) was more frequent in the ESD group than in the C-EMR group $(p=0.0341)$.The mean procedure time was higher in the ESD group than in the C-EMR group $(56 \pm 20 \mathrm{~min}$ vs. $21 \pm 11 \mathrm{~min}$, respectively, $\mathrm{p}<0.005)$. En bloc resection and complete curative resection rates were similar in both groups [ESD vs. C-EMR: $93.6 \%$ vs. $86.7 \%, \mathrm{p}=$ not significant $(\mathrm{NS}) ; 87.2 \%$ vs. $80.0 \%, \mathrm{p}=$ NS, respectively]. Perforation rate was $6.4 \%(n=3)$ in the ESD group and $3.3 \%(n=1)$ in the C-EMR group ( $p=N S)$. Endoclipswere used for the two perforations that occurred during ESD; the perforationswere managed conservatively. The patient in the C-EMR group who had a perforation developed abdominal pain in the evening following surgery. Surgery was required in this patientbecause CT revealed peritonitis with free air and ascites. Postoperative evaluation revealed a pinhole at the edge of the resected specimen, which probably occurred during circumferential mucosal incision. Delayed bleeding occurred in onepatients (2.1\%) from the ESD group; no patientin the C-EMR grouphad delayed bleeding. Endoclipswere used to successfully controlall bleeding cases;no blood transfusions were required. 
Table 1. Clinical characteristics of patients treated with endoscopic submucosal dissection and endoscopic mucosal resection after circumferential mucosal incision with colorectal tumors with a diameter of $20-30 \mathrm{~mm}$

\begin{tabular}{|l|l|l|l|}
\hline & ESD & C-EMR & p value \\
\hline Number of tumors & 47 & 30 & \\
\hline Gender $(\mathrm{M} / \mathrm{F})$ & $27 / 12$ & $17 / 13$ & NS \\
\hline Age (mean \pm SD; years) & $68.9 \pm 11$ & $67.8 \pm 11$ & NS \\
\hline (range) & $39-86$ & $42-83$ & \\
\hline Macroscopic type & & & \\
\hline Is & 8 & 3 & \\
\hline LST-G & 15 & 19 & 0.007 \\
\hline LST-NG & 24 & 8 & 0.034 \\
\hline Tumor size (mean \pm SD) & $25.3 \pm$ & $23.4 \pm 3.4$ & NS \\
& 3.8 & & \\
\hline Location (right/left/rectum) & $21 / 15 / 11$ & $15 / 9 / 6$ & NS \\
\hline
\end{tabular}

ESD, endoscopic submucosal dissection; C-EMR,endoscopic mucosal resection after circumferential mucosal incision; Is, polypoid subtype 0-I sessile;LST-G, laterally spreading tumor of granular type; LST-NG, laterally spreading tumor of nongranular type; SD, standard deviation; NS, not significant

Table 2. Clinical outcomes among patients treated with endoscopic submucosal dissection and endoscopic mucosal resection after circumferential mucosal incision with colorectal tumors with a diameter of $20-30 \mathrm{~mm}$

\begin{tabular}{|l|l|l|l|}
\hline & ESD & C-EMR & p value \\
\hline Number of tumors & 47 & 30 & \\
\hline Procedure times & & & \\
\hline (mean \pm SD; min) & $56 \pm 20$ & $21 \pm 11$ & $<0.005$ \\
\hline (range) & $25-120$ & $6-53$ & \\
\hline En bloc resection (\%) & $44(93.6 \%)$ & $26(86.7 \%)$ & NS \\
\hline Complete resection $(\%)$ & $41(87.2 \%)$ & $24(80.0 \%)$ & NS \\
\hline Complications & & & \\
\hline Perforation & $3(6.4 \%)$ & $1(3.3 \%)$ & $\mathrm{NS}$ \\
\hline Delayed bleeding & $1(2.1 \%)$ & 0 & $\mathrm{NS}$ \\
\hline Recurrence rate & 0 & 0 & \\
\hline $\begin{array}{l}\text { Follow-up (median; } \\
\text { month) }\end{array}$ & 18 & 26.5 & $<0.01$ \\
\hline
\end{tabular}

ESD, endoscopic submucosal dissection; C-EMR,endoscopic mucosal resection after circumferential mucosal incision; SD, standard deviation; NS, not significant

Table 3. Comparison of pathologies for resected tumor specimens among patients treated with endoscopic submucosal dissection and endoscopic mucosal resection after circumferential mucosal incision with colorectal tumors with a diameter of 20-30 mm

\begin{tabular}{|l|l|l|l|}
\hline & ESD & C-EMR & p value \\
\hline Number of tumors & 47 & 30 & \\
\hline Adenoma & $1(2.1 \%)$ & $13(43 \%)$ & 0 \\
\hline Invasion depth of adenocarcinoma & & & \\
\hline Mucosal & $42(89 \%)$ & $14(47 \%)$ & 0 \\
\hline Shallow submucosal & $1(2.1 \%)$ & $1(3.3 \%)$ & $\mathrm{NS}$ \\
\hline Massive submucosal & $3(6.4 \%)$ & $2(6.7 \%)$ & $\mathrm{NS}$ \\
\hline Lymphovascular involvement & $1(2.1 \%)$ & $2(6.7 \%)$ & $\mathrm{NS}$ \\
\hline
\end{tabular}

ESD, endoscopic submucosal dissection; C-EMR,endoscopic mucosal resection after circumferential mucosal incision; NS, not significant

Shallow submucosal invasion: tumor invasion depth $<1000 \mu \mathrm{m}$

Massive submucosal invasion: tumor invasion depth $\geq 1000 \mu \mathrm{m}$ 
Although the median follow-up period was shorter in the ESD group (18 months) than in the C-EMR group (26.5 months) $(\mathrm{p}<$ $0.01)$, cancer or adenoma recurrence was not detected in either group during the follow-up period. Histopathological features ofthe resected tumor specimens are shown in Table 3.

Fewer adenomas were detected in the ESD group than in the C-EMR group $(p=0)$. Conversely, the proportion of intramucosal carcinoma was higher in the ESD group than in the C-EMR group $(p=0)$. Shallow submucosal invasion was detected in one patient each from the ESD group and C-EMR group (NS). Massive submucosalinvasionwas detected in three patients from the ESD groupand two patients from the C-EMR groups (NS). Lymphovascular involvement was detected in one patients in the ESD and two patients in the C-EMR groups (NS). Threetumors in the ESD group were resected en blocwithout complete resection (massive submucosal invasion with lymphovascular involvement, $\mathrm{n}=1$; massive submucosal invasion without lymphovascular involvement, $\mathrm{n}=2$ ). Two tumors in the C-EMR groupwere resected enbloc without complete resection (massive submucosal invasion with lymphovascular involvement, $\mathrm{n}=2$ ).

All patients with massive tumor invasion and/or lymphovascular involvementin both groups were treated with additional radical
surgery.There were two patients in the ESD groupand one in the C-EMR group who underwent ablation using a hemostatic forceps or argon plasma coagulation for residual tumors difficult to remove with additional snaring after piecemeal resection. Table4 compares the clinical characteristics and outcomes between tumor specimens excised usingen bloc and piecemealresections in the ESD group.

No significant differences were observed between the two subgroupsfor age, tumor size, location, and macroscopic type.For LSTs of nongranular type, the percentage of tumors with the nonlifting sign and preoperative biopsy, and pathology.Table 5 compares the clinical characteristics and outcomes between tumor specimens excised usingen bloc and piecemealresections in the C-EMR group.

No significant differences were observed between the two subgroupsfor age, tumor size, location, and macroscopic type, and the percentage of preoperative biopsy. Of LST-NGs, the percentage of tumors with the nonlifting sign was $16.7 \%(1 / 6)$ in the en blocC-EMRsubgroup and $100.0 \%(2 / 2)$ in the piecemeal CEMRsubgroup ( $\mathrm{p}=0.035)$. No significant differences in the histopathological findings were observed between the two subgroups. There were no tumors that underwent attempted resection before endoscopic treatment.

Table 4. Comparison of clinical characteristics and outcomes among en bloc and piecemeal resected tumor specimens by endoscopic submucosaldissectionin patients with colorectal tumors with a diameter of $20-30 \mathrm{~mm}$

\begin{tabular}{|l|l|l|l|}
\hline & En bloc & Piecemeal & p value \\
\hline Number of tumors & 44 & 3 & \\
\hline Age (mean \pm SD; years) & $68.2 \pm 11$ & $79.3 \pm 4$ & NS \\
\hline Tumor size (mean \pm SD) & $25.3 \pm 4$ & $26.0 \pm 2$ & NS \\
\hline Location (right/left/rectum) & $21 / 14 / 9$ & $0 / 1 / 2$ & NS \\
\hline Macroscopic type & & & \\
\hline (Is/LST-G/LST-NG) & $8 / 13 / 2023$ & $0 / 2 / 1$ & NS \\
\hline Presence of nonlifting sign & & & \\
\hline (Is/LST-G/LST-NG) & $0 / 0 / 3$ & $0 / 0 / 1$ & NS \\
\hline Preoperative biopsy & & & \\
\hline (Is/LST-G/LST-NG) & $0 / 6 / 4$ & $0 / 0 / 1$ & NS \\
\hline Pathology & & & \\
\hline Adenoma & 1 & 0 & NS \\
\hline Invasion depth of adenocarcinoma & & & \\
\hline Mucosal & 37 & 3 & NS \\
\hline Shallow submucosal & 1 & 0 & NS \\
\hline Massive submucosal & 3 & 0 & NS \\
\hline Lymphovascular involvement & $1(2.3 \%)$ & 0 & NS \\
\hline
\end{tabular}

ESD, endoscopic submucosal dissection; C-EMR,endoscopic mucosal resection after circumferential mucosal incision; Is, polypoid subtype 0-I sessile;LST-G, laterally spreading tumor of granular type; LST-NG, laterally spreading tumor of nongranular type; SD, standard deviation; NS, not significant

Shallow submucosal invasion: tumor invasion depth $<1000 \mu \mathrm{m}$

Massive submucosal invasion: tumor invasion depth $\geq 1000 \mu \mathrm{m}$

The typical procedures in the ESD and C-EMR cases are shown in Figures2and3, respectively. Figure 4 shows the presence of the nonlifting sign in LST-NGs.

Many studies reported that local recurrence is common after conventional EMR and endoscopic piecemeal mucosal resection (EPMR) for colorectal tumors [9, 11, 22-24]. En bloc resection rates, however, have been reported to be excellent (80\%-98.6\%); recurrence rates were reported to be lower in patients who underwent ESD than in those who underwent EMR [13, 15-19].Although local recurrence rates in EMR are generally high [10-12, 25], no recurrence was observed in this study, even in patients treated with piecemeal C-EMR. Circumferential mucosal incision as the first step in C-EMR may reduce the local recurrence rate 
Table 5. Comparison of clinical characteristics and outcomes among en bloc and piecemeal resected tumor specimens by endoscopic mucosal resection after circumferential mucosal incision in patients with colorectal tumors with a diameter of 20-30 mm

\begin{tabular}{|l|l|l|l|}
\hline & En bloc & Piecemeal & p value \\
\hline Number of tumors & 26 & 4 & \\
\hline Age (mean \pm SD; years) & $68.1 \pm 11$ & $65.5 .3 \pm 12$ & NS \\
\hline Tumor size (mean \pm SD) & $23.5 \pm 3.2$ & $22.5 \pm 4.3$ & NS \\
\hline Location (right/left/rectum) & $13 / 7 / 6$ & $2 / 2 / 2000$ & NS \\
\hline Macroscopic type & & & \\
\hline (Is/LST-G/LST-NG) & $3 / 17 / 2006$ & $0 / 2 / 2$ & NS \\
\hline Presence of nonlifting sign & & & \\
\hline (Is/LST-G/LST-NG) & $0 / 1 / 1$ & $0 / 1 / 2$ & 0.035 \\
\hline Preoperative biopsy & & & \\
\hline (Is/LST-G/LST-NG) & $0 / 4 / 3$ & $0 / 0 / 2$ & NS \\
\hline Pathology & & & \\
\hline Adenoma & 10 & 3 & NS \\
\hline Invasion depth of adenocarcinoma & & & \\
\hline Mucosal & 13 & 1 & NS \\
\hline Shallow submucosal & 1 & 0 & NS \\
\hline Massive submucosal & 2 & 0 & NS \\
\hline Lymphovascular involvement & $2(7.7 \%)$ & 0 & NS \\
\hline
\end{tabular}

ESD, endoscopic submucosal dissection; C-EMR,endoscopic mucosal resection after circumferential mucosal incision; Is, polypoid subtype 0-I sessile;LST-G, laterally spreading tumor of granular type; LST-NG, laterally spreading tumor of nongranular type; SD, standard deviation; NS, not significant

Shallow submucosal invasion: tumor invasion depth $<1000 \mu \mathrm{m}$

Massive submucosal invasion: tumor invasion depth $\geq 1000 \mu \mathrm{m}$

Figure 2. Endoscopic submucosal dissection

(a) A 30-mm-diameter laterally spreading rectal tumor. (b) Submucosal injection with hyaluronic acid. (c) Circumferential incision with a needle knife. (d) Submucosal dissection with a dual knife. (e) After resection. (f) The resected specimen.
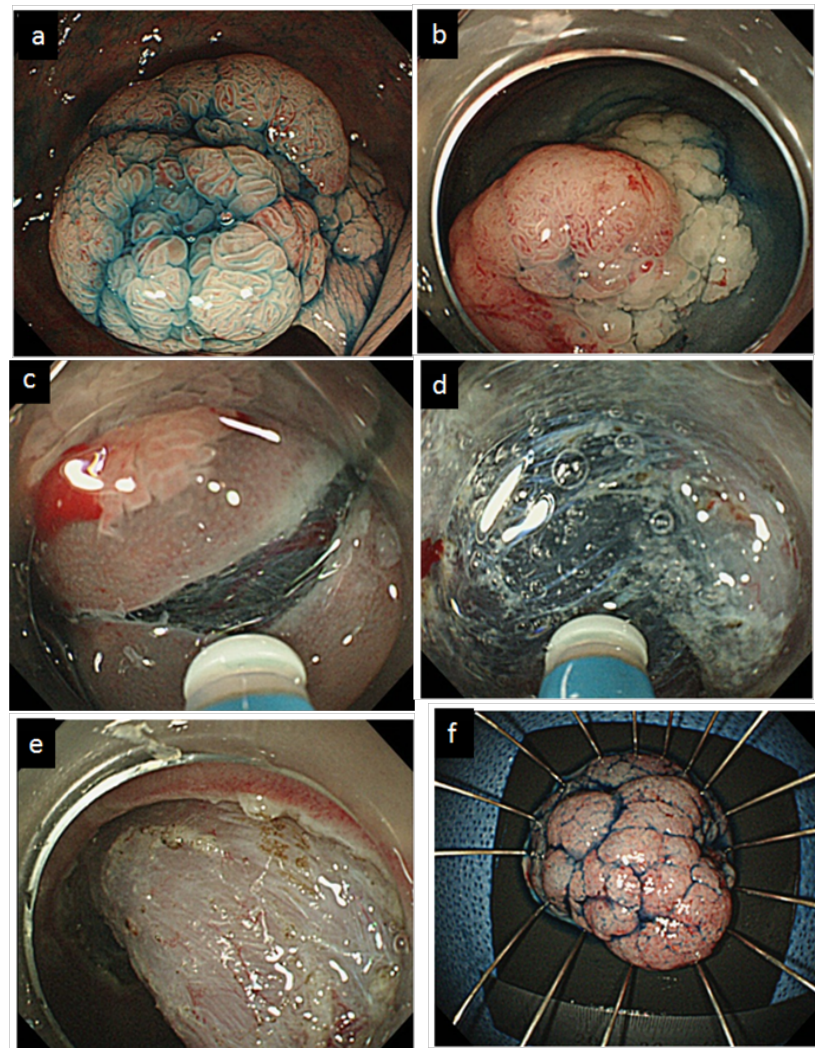
Figure 3. Endoscopic mucosal resection after circumferential mucosal incision.

(a) A 28-mm-diameter laterally spreading cecal tumor. (b) Submucosal injection with 10\% glycerol. (c) Circumferential mucosal incision with a needle knife. (d) Snaring with a 33-mm oval snare. (e) After resection. (f) The resected specimen.
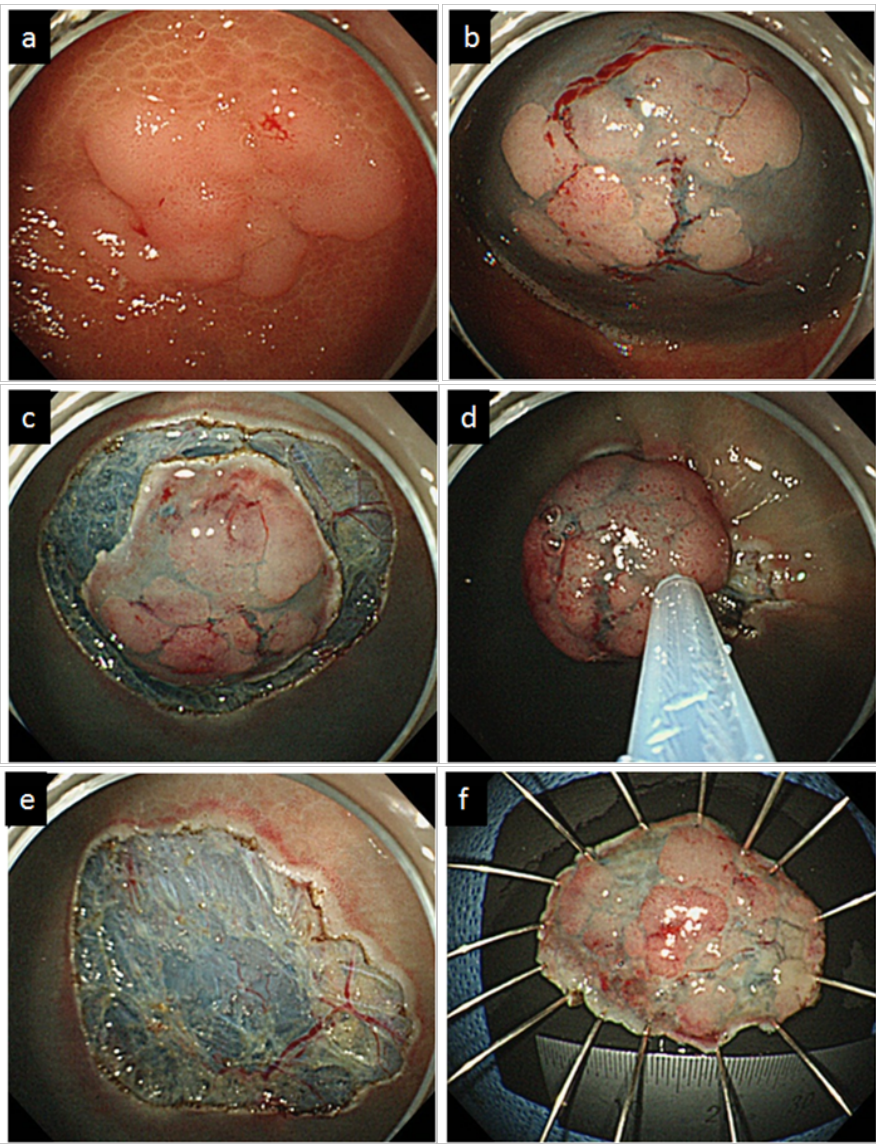

Figure 4. A case of a laterally spreading,nongranular type tumor with the nonlifting sign.

(a) A 25-mm-diameter laterally spreading tumor in the transverse colon. (b) The center of the tumor was poorly elevated after submucosal injection.
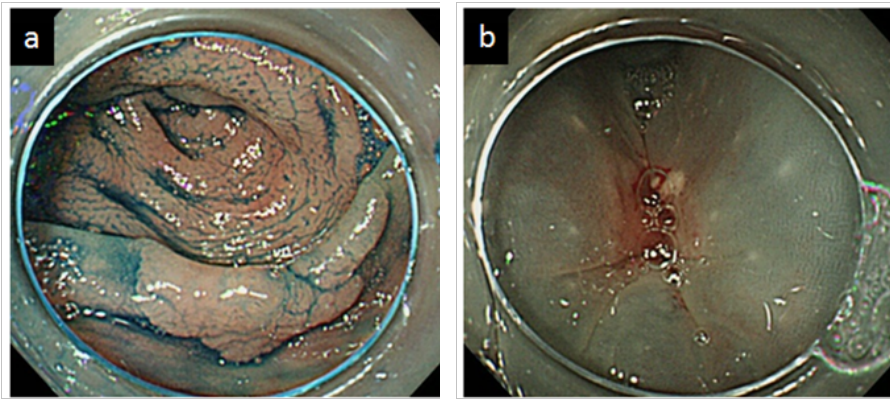

similar to those achieved in ESD.

\section{Tumors suitable for C-EMR}

Our results showing that easily visible LSTs in the presence of good lifting sign after submucosal injection with a diameter of 20-30 mm were best suited for C-EMR.The circumferential mucosal incision should encompass the entire muscularis mucosa, exposing the submucosal layer and facilitating resection of the whole tumor. Although adequate trimming of the submucosal layer allows resection of larger tumors, we prefer setting a maximum limit of the tumor size to $30 \mathrm{~mm}$ because of lateral slip of the snare in the tumor margin. Tumors at the end of the cecum, where risk of perforation during ESD is higher, are also good candidates for C-EMR.

From a pathological viewpoint, tumors wherein piecemeal resection in the minimum number of divisions is generally acceptable are also suitable for C-EMR. LST-G homogeneous type tumors, often diagnosed as adenomas and intramucosal carcinomas [19, 26], are suitable candidates for C-EMR. Even in nodular mixed typeLST-Gs, en bloc resection of large nodes that may contain cancerous tissuehas little influence on the pathological diagnosis. It was consideredthat the lower proportion of intramucosalcarcinomas and higher proportion of adenomas in the C-EMR group compared with the ESD group in this study were due to the selection bias because endoscopists recognized that LST-NG and LST-G with noduleshave higher cancer-bearing rates.

Generally, ESD should be performed for LST-NGs with submucosal fibrosis and multifocal invasion of the submucosa [9]. Piecemeal resection should be avoided.

En bloc resection rate in the ESD group in our study was comparable to that in other reports [13, 15-19]. 
The en bloc resection rate in the C-EMR group in the present study was higher than the rates given in other reports of EMR for colorectal tumors $\geq 20 \mathrm{~mm}[18,27]$ because ensuring clear lateral margins by making a circumferential mucosal incision and trimming of the submucosal layer may reduce the risk of lateral slip during snaring of the entire tumor, and we perfomed C-EMR for the tumors $<30 \mathrm{~mm}$. C-EMR was found to be appropriate for $<30$-mm-diameter LST-NGs with good response after submucosal injection and good visibility of the entire tumor. In contrast, the percentage of LST-NG with the nonlifting sign in the piecemealC-EMRsubgroup wassignificantly higher than that in theenblocC-EMRsubgroup. This showed that C-EMR was unsuitable for LST-NGs with the nonlifting sign (Fig. 4). We consider that successful C-EMR requires the presence of good lifting sign after submucosal injection. For similar reasons, recurrent tumors or residual intramucosal tumors with the nonlifting sign after endoscopic resection should be treated using ESD because of submucosal fibrosis.

\section{Recurrence after C-EMR}

Sakamoto et al. reported that removal offiveor more neoplasm specimens was an independent risk factor for local recurrence after EPMR [28]. In this study, no recurrence was observed in the C-EMR group, including the 4 piecemeal resection cases (two pieces, $\mathrm{n}=3$; three pieces, $\mathrm{n}=1$ ). For many cases in which EPMR is performed, the pathological diagnosis is underestimated[29]. Strict follow-up is necessary for patients who undergo piecemeal C-EMR because of the potential burn effect, especially those histopathologically diagnosed with intramucosal carcinoma.The burn effect may cause underestimation of vertical resection margins, lymphovascular involvement, and tumor budding. Although most recurrences are detected within 6 months after endoscopic treatment [12],no recurrence was observed in this study at follow-up colonoscopy performed 3 or 6 months after endoscopic therapy.Because the median follow-up periods in this study were very short, patients with colorectal tumors should be continuously followed up.

\section{Advantages of the C-EMR method}

Eun-Jung Lee et al. reported the effectiveness and outcomes of EMR, C-EMR, which they called EMR-precutting, and ESD [27]. Their enbloc resection rate of C-EMR was $65.2 \%$, which was lower than ours because they performed C-EMR as a step to introduce ESD. They stated that C-EMR was effective for relatively small tumors. We agree with their conclusion, as mentioned above. Toyonaga et al. stated that C-EMR, which they called simplified ESD, was a welcome addition to ESD for inexperienced endoscopists because it required less technical proficiency than ESD [30]. The procedure time for resection using C-EMR may be shorter than that using ESD.

The differences in the cost among ESD and C-EMR depend on the device used for the endoscopic procedures. C-EMR is less expensive than ESD using a sigle device because the needle knife used for mucosal incision is reusable, and the main device is only a snare. Moreover, the cost in the case of ESD using more than 2 devices is furthermore higher than those of C-EMR. From the viewpoint of medical treatment fees in Japan, ESD (183700 JPY) costs about 3.7 times as much as EMR (50000 JPY). Considering this reason, if superficial colorectal tumor $<20-30 \mathrm{~mm}$ is curatively treated by C-EMR, the economic benefits would be higher.
Thus, C-EMR is a more useful endoscopic treatment modality than ESD with regard to operation time, expertise, experience, and cost-effectiveness.

\section{Limitations}

The limitationsofthis study include its single-centerretrospectivenature, selection bias due to tumor morphology, andthe relatively smallnumber ofcases as well asvariations in the endoscopes,skill level of the operators, and short follow-up periods.

\section{Conclusions}

Our results showed that C-EMR is feasible and effective with outcomes equivalent to those of ESD for treating large colorectal tumors with a diameter of $20-30 \mathrm{~mm}$ when performed in cases with appropriate indications.Further prospective studies are warranted.

\section{References}

[1]. Ahmad NA, Kochman ML, Long WB, Furth EE, Ginsberg GG. (2002) Efficacy, safety, and clinical outcomes of endoscopic mucosal resection: a study of 101 cases. Gastrointest Endosc55:390-396

[2]. Yokota T, Sugihara K, Yoshida S. (1994) Endoscopic mucosal resection for colorectal neoplastic lesions. Dis Colon Rectum37:1108-1111

[3]. Soetikno RM, Gotoda T, Nakanishi Y, Soehendra N. (2003)Endoscopic mucosal resection. Gastrointest Endosc57:567-579

[4]. Hurlstone DP, Sanders DS, Cross SS, et al. (2004) Colonoscopic resection of lateral spreading tumours: a prospective analysis of endoscopic mucosal resection. Gut53:1334-1339

[5]. Kiesslich R, Neurath MF. (2004) Endoscopic mucosal resection: an evolving therapeutic strategy for non-polypoid colorectal neoplasia. Gut53:12221224

[6]. Saito Y, Fujii T, Kondo H, et al. (2001) Endoscopic treatment for laterally spreading tumors in the colon. Endoscopy33:682-686

[7]. Tanaka S, Haruma K, Oka S, et al.(2001) Clinicopathologic features and endoscopic treatment of superficially spreading colorectal neoplasms larger than $20 \mathrm{~mm}$. Gastrointest Endosc54:62-66

[8]. Kudo S, Kashida H, Tamura T, et al. (2000) Colonoscopic diagnosis and management of nonpolypoid early colorectal cancer. World J Surg24:10811090

[9]. Uraoka T, Saito Y, Matsuda T, et al.(2006) Endoscopic indications for endoscopic mucosal resection of laterally spreading tumours in the colorectum. Gu55:1592-1597

[10]. Conio M, Repici A, Demarquay JF, Blanchi S, Dumas R, Filiberti R. (2004) EMR of large sessile colorectal polyps. Gastrointest Endosc 60:234-241

[11]. Fukami N, Lee JH. (2006) Endoscopic treatment of large sessile and flat colorectal lesions. Curr Opin Gastroenterol22:54-59

[12]. Brooker JC, Saunders BP, Shah SG, Thapar CJ, Suzuki N, Williams CB. (2002) Treatment with argon plasma coagulation reduces recurrence after piecemeal resection of large sessile colonic polyps: a randomized trial and recommendations. Gastrointest Endosc55:371-375

[13]. Fujishiro M, Yahagi N, Kakushima N, et al.(2007) Outcomes of endoscopic submucosal dissection for colorectal epithelial neoplasms in 200 consecutive cases. Clin Gastroenterol Hepatol5:678-683; quiz 645

[14]. Hurlstone DP, Atkinson R, Sanders DS, Thomson M, Cross SS, Brown S.(2007) Achieving R0 resection in the colorectum using endoscopic submucosal dissection. Br J Surg94:1536-1542

[15]. Tamegai Y, Saito Y, Masaki N, et al. (2007) Endoscopic submucosal dissection: a safe technique for colorectal tumors. Endoscopy39:418-422

[16]. Tanaka S, Oka S, Kaneko I, et al.(2007) Endoscopic submucosal dissection for colorectal neoplasia: possibility of standardization. Gastrointest Endosc66:100-107

[17]. Yoshida N, Wakabayashi N, Kanemasa K, et al. (2009) Endoscopic submucosal dissection for colorectal tumors: technical difficulties and rate of perforation. Endoscopy41:758-761

[18]. Saito Y, Fukuzawa M, Matsuda T, et al.(2010) Clinical outcome of endoscopic submucosal dissection versus endoscopic mucosal resection of large colorectal tumors as determined by curative resection. Surg Endosc24:343-352

[19]. Nishiyama H, Isomoto H, Yamaguchi N, et al.(2010) Endoscopic submucosal dissection for laterally spreading tumours of the colorectum in 200 consecutive cases. Surg Endosc24:2881-2887

[20]. Participants in the Paris Workshop. (2002) The Paris endoscopic classification of superficial neoplastic lesions: esophagus, stomach, and colon: November 30 to December 1. Gastrointest Endosc58:S3-43 
Mochizuki Y et al (2013) Endoscopic mucosal resection after circumferential mucosal incision of large colorectal tumors: comparison with endoscopic submucosal dissection. Int $\mathrm{J}$

[21]. Schlemper RJ, Riddell RH, Kato Y, et al.(2000) The Vienna classification of gastrointestinal epithelial neoplasia. Gut47:251-255

[22]. Seo GJ, Sohn DK, Han KS, et al.(2010) Recurrence after endoscopic piecemeal mucosal resection for large sessile colorectal polyps. World J Gastroenterol16:2806-2811

[23]. Iishi H, Tatsuta M, Iseki K, et al. (2000) Endoscopic piecemeal resection with submucosal saline injection of large sessile colorectal polyps. Gastrointest Endosc51:697-700.

[24]. Higaki S, Hashimoto S, Harada K, et al.(2003) Long-term follow-up of large flat colorectal tumors resected endoscopically. Endoscopy35:845-849

[25]. Hotta K, Fujii T, Saito Y, Matsuda T. (2009) Local recurrence after endoscopic resection of colorectal tumors. Int J Colorectal Dis24:225-230

[26]. Kim BC, Chang HJ, Han KS, et al. (2011) Clinicopathological differences of laterally spreading tumors of the colorectum according to gross appearance. Endoscopy43:100-107
[27]. Lee EJ, Lee JB, Lee SH, Youk EG. (2012) Endoscopictreatment of largecolorectal tumors: comparison of endoscopic mucosal resection, endoscopic mucosal resection-precutting, and endoscopic submucosal dissection. Surg Endosc8:2220-2230

[28]. Sakamoto T, Matsuda T, Otake Y, Nakajima T, Saito Y. (2012) Predictive factors of local recurrence after endoscopic piecemeal mucosal resection. J Gastroenterol47:635-640

[29]. Yoshida N, Naito Y, Yagi N, Yanagisawa A. (2012) Importance of histological evaluation in endoscopic resection of early colorectal cancer. World J Gastrointest Pathophysiol3:51-59

[30]. Toyonaga T, Man-i M, Chinzei R, et al.(2010) Endoscopic treatment for early stage colorectal tumors: the comparison between EMR with small incision, simplified ESD, and ESD using the standard flush knife and the ball tipped flush knife. Acta Chir Iugos157:41-46 